\title{
Morphological Control of Silica Nanomaterials Using Sugar-Based Hydrogel with Different Anions
}

\author{
Sung Ho Jung, Eunjeong Kim, Soo Jin Lee, Chang Geun Lee, Jin-Kook Lee, Shim Sung Lee, and Jong Hwa Jung \\ Department of Chemistry (BK21) and Research Institute of Natural Science, Gveongsang National Lniversitv: \\ Jinit 660-701, Korea. "E-mail: jonghwaágmac.kr \\ Department of Polymer Science and Engineering, Pusan Kational Lniversitw, Pusan 609-735, Korea \\ Received Harch 11, 2008
}

Key Words : Crown ether. Hydrogel. Sol-gel reaction. Spherical silica. Tubular silica

Exploitation of new organic gelators which can gelate various organic solvents has become an active area of research. ${ }^{1.9}$ In contrast to polymer gels, organogels are comprised of fibrous aggregates of low molecular-weight compounds formed by non-covalent interactions. Organogels exhibit various superstructures, reflecting the unique monomeric structure of each gelator. Certain cholesterol derivatives can gelate even tetraethoxy silane (TEOS), which results in a gel of silica formed by sol-gel polymerization. ${ }^{10,11}$ Interestingly, sol-gel polymerization of gelated TEOS solutions followed by calcination afforded novel hollow fiber silica nanostructures because the organogel fibers act as a template to create an interior tube during the polymerization process. $^{9-15}$

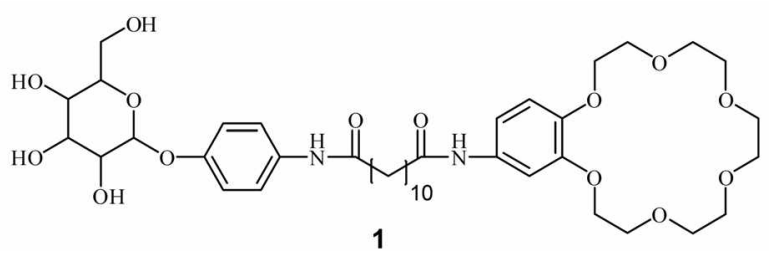

If various morphologies of the self-assembled gels induced by gelator complex with the metal ion can be prepared various morphologies of silica nanomaterials can be easily produced by sol-gel transcription. In addition, if the metal cromn complexes of this gelator act as a template in the TEOS sol-gel polymerization process, it follows that metal cations are left inside the silica nanomaterials after calcination. To realize this intriguing idea. we synthesized the crown-appended sugar gelator 1 having a sugar moiety as an aggregate-forming site and a crown moiety as a metalbinding site. Herein. we describe the preparation of selfassembled organic fibrillar and spherical superstructures and their sol-gel transcription to yield tubular and hollow spherical structures of silica.

Crown-appended sugar gelator 1 was synthesized wia a convergent strategy in which dodecanedioyl dichloride was attached to aminophenyl glucopyranoside using TEA mediated coupling conditions. The products were purified using silica gel columu cluromatography. The gelation ability was tested in water. ${ }^{15}$ Compound 1 in the presence of metal ion such as $\mathrm{AgNO}_{3}, \mathrm{AgClO}_{4} . \mathrm{NaNO}_{3}$. and $\mathrm{NaClO}_{4}$ formed a gel in water, indicating that gelator 1 can act as a template to produce the various structures of silica nanomaterials.

The superstructures constructed from lyydrogel 1 in the presence of metal ions observed by SEM or TEM. The hydrogel formed in the presence of $\mathrm{AgNO}_{3}$ was very different from that formed in the presence of $\mathrm{AgClO}_{4}$ (Figure 1). The presence of $\mathrm{AgNO}_{3}$ afforded a hydrogel with a
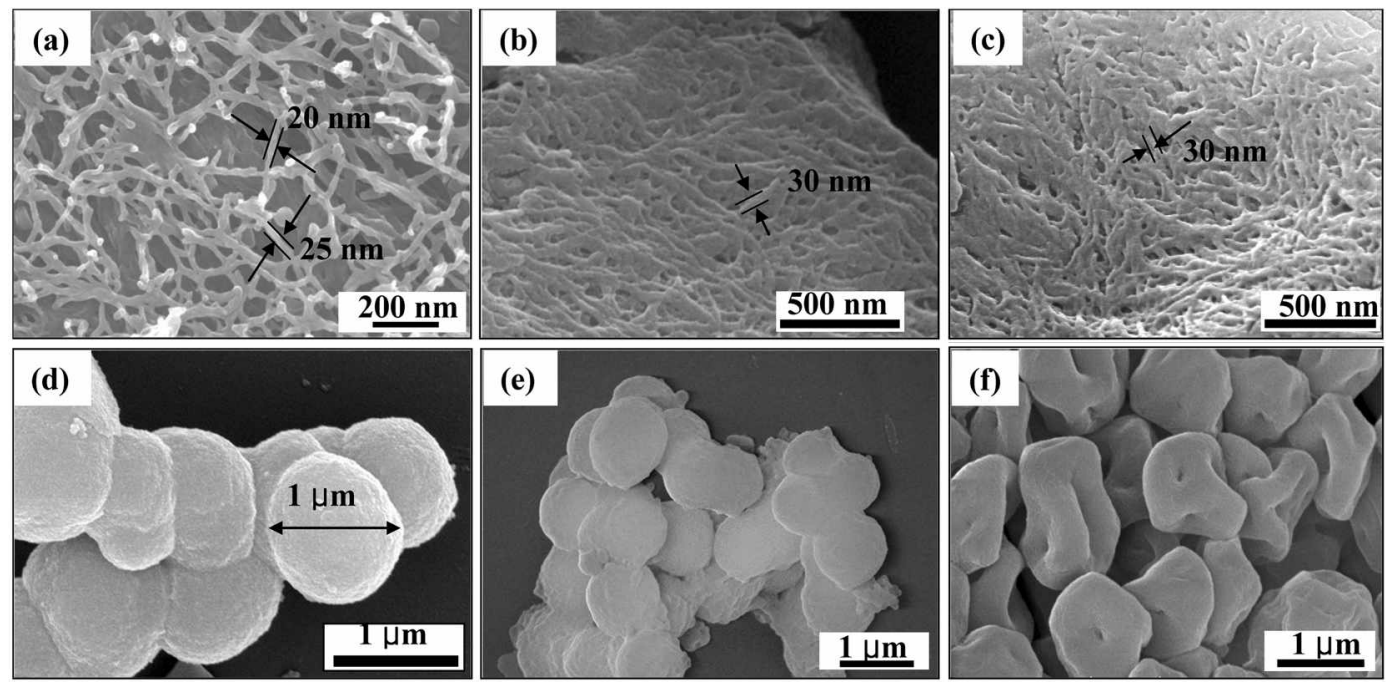

Figure 1. SEM images of the hydrogels (a) $1+\mathrm{AgNO}_{3}$, (b) $1+\mathrm{NaNO}_{3}$, (c) $1+\mathrm{RbNO}_{3}$, (d) $1+\mathrm{AgClO}_{4}$, (e) $1+\mathrm{NaClO}_{4}$ and (f) $1+\mathrm{CsClO}_{4}$. 

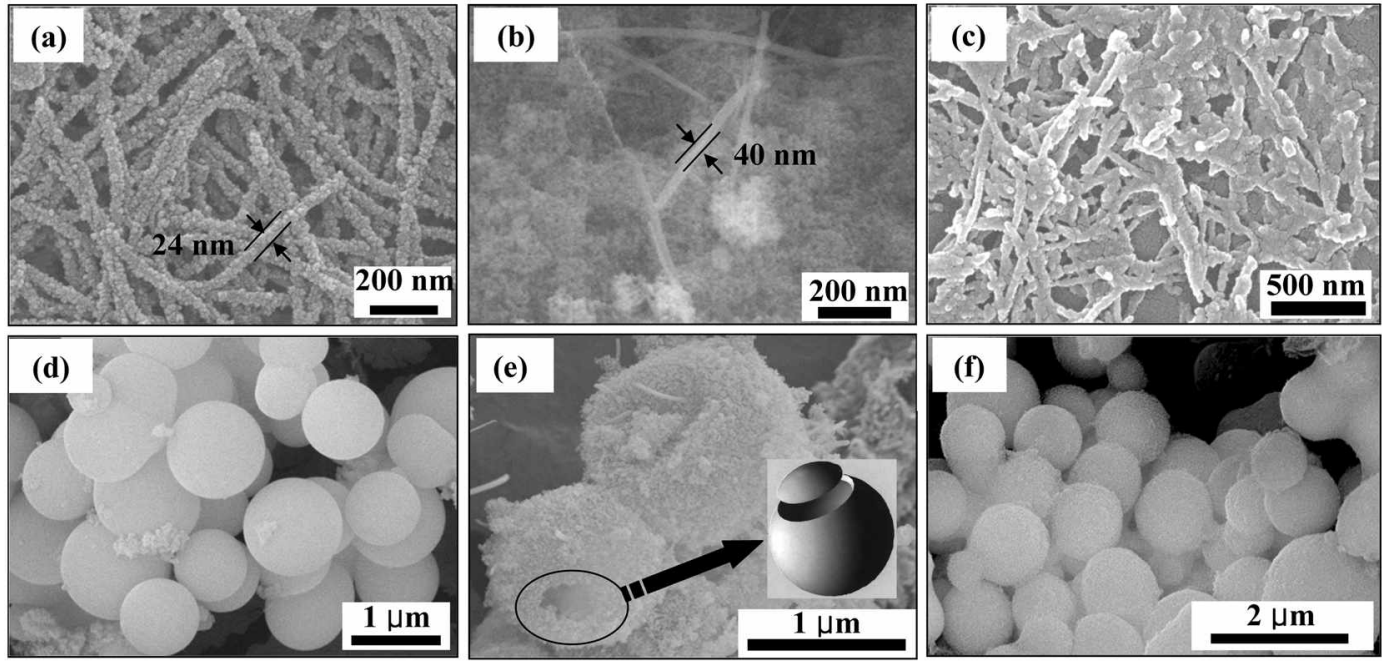

Figure 2. SEM images of the silica structures obtained from hydrogels (a) $1+\mathrm{AgNO}_{3}$, (b) $1+\mathrm{NaNO}_{3}$, (c) $1+\mathrm{RbNO}_{3}$, (d) $1+\mathrm{AgClO}$, (e) $1+\mathrm{NaClO}_{4}$ and (f) $1+\mathrm{CsClO}_{4}$ after calcinations by sol-gel transcription.

fibrous network structure, $\approx 20-25 \mathrm{~nm}$ in diameter. The fibers were partially twisted in a helical fashion (arrows in Figure la), a type of superstructure comparable to the organogels prepared with azobenzene-appended cholesterol gelators. In contrast, the hydrogel in the presence of $\mathrm{AgClO}_{4}$ revealed a spherical structure with $\mathrm{I} \mu \mathrm{m}$ diameter. These results suggest that different metal ions play a role in controlling the morphology of hydrogels. In addition, in the presence of $\mathrm{NaNO}_{3}$ and $\mathrm{NaClO}_{+}$the superstructures of hydrogel 1 were similar to those formed with $\mathrm{AgNO}_{3}$ and $\mathrm{AgClO}_{4}$. These results support the view that the morphology of hydrogel 1 was more strongly dependent on the counter anion than the cation in the metal salts. Furthernnore. maybe major factor for morphological difference between $\mathrm{NO}_{3}{ }^{-}$and $\mathrm{ClO}_{4}{ }^{-}$is due to coordinating nature. The coordination nature of $\mathrm{NO}_{3}{ }^{-}$is much stronger than that of $\mathrm{ClO}_{4}{ }^{-16}$.

To transcribe the self-assembled hydrogel with metal ions into the silica nanomaterials. we carried out sol-gel polymerization of TEOS in the presence of metal ions as described in the Experimental Section. After calcination. we obtained SEM images of the silica nanomaterials obtained by using hydrogel 1 in the presence of either $\mathrm{AgNO}_{3}$ or $\mathrm{AgClO}_{4}$ as templates (Figure 2). In addition. the sol-gel reaction of TEOS in the presence of $\mathrm{Ag}^{-}$was carried out in neutral condition to prevent precipitation formation of $\mathrm{Ag}$ salt. A tubular structure with diameter of $24-30 \mathrm{~nm}$ and several $\mu \mathrm{m}$ in length was obtained when $\mathrm{AgNO}_{3}$ was present in the reaction mixture, whereas a spherical structure with 1.0-1.2 $\mu \mathrm{m}$ outer diameter was obtained with $\mathrm{AgClO}_{4}$. These results indicate that the tubular or the spherical structures of hydrogel 1 obtained with $\mathrm{AgNO}_{3}$ or $\mathrm{AgClO}_{4}$. respectively. were successfully transcribed into the silica nanostructure. Similarly tubular and spherical structures of silica nanomaterials were obtained from hydrogel $\mathbf{1}$ in the presence of $\mathrm{NaNO}_{3}$ and $\mathrm{NaClO}_{4}$, respectively.

To further corroborate that the hydrogel superstructure really acts as a template for the growth of the silica nanotube. we prepared TEM micrographs after removal of 1 by calcination. As shown in Figure 3, the silica nanotube in the presence of $\mathrm{AgNO}$ or $\mathrm{NaNO}_{3}$ shows a fibrous structure with 24-40 $\mathrm{nm}$ outer diameters and a few micrometers length. The yield for the silica nanotube was almost $100 \%$. On the other hand, the silica obtained from lyydrogel 1 in the presence of $\mathrm{AgClO}_{4}$ or $\mathrm{NaClO}_{4}$ shows a hollow inner cavity with $1.0-1.2 \mu \mathrm{m}$ inner diameter. In addition, the hollow structure of the silica sphere consists of a monolayer structure. Earlier results consistently supported the view that the construction of the hollow fiber and spherical silica is profoundly related to the specific $\mathrm{M}^{+}$-benzo-18-cromll- 6 interaction. It is now clear that the structure of the silica product is more closely related to the specific influence of the cationic charge on the sol-gel polymerization process. When the sol-gel polymerization is carried out in the presence of metal ion solution. the propagation species is considered to be anionic. Hence, the anionic oligomeric
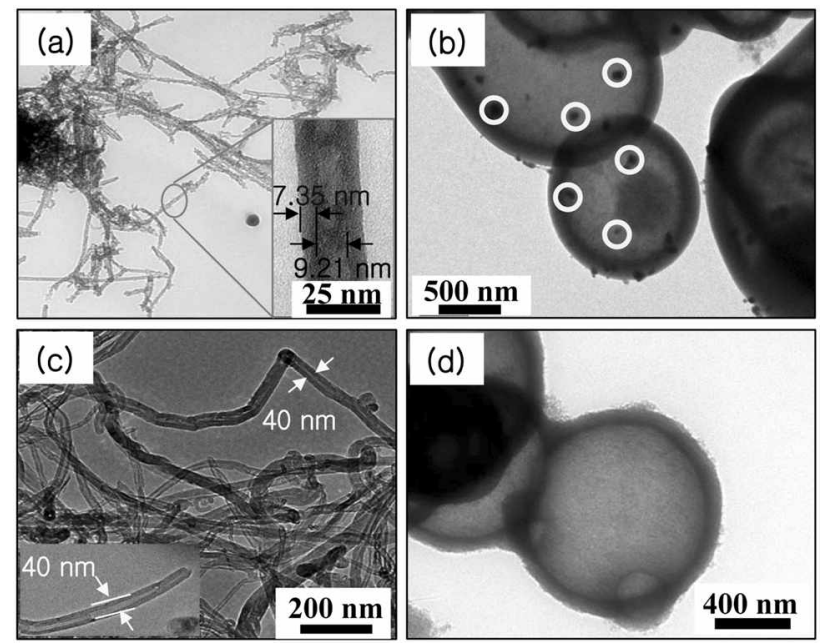

Figure 3. TEM images of the silica structures obtained from hydrogels (a) $1+\mathrm{AgNO}_{3}$, (b) $1+\mathrm{AgClO}_{4}$, (c) $1+\mathrm{NaNO}_{3}$ and (d) $1+\mathrm{NaClO}_{4}$ atter calcinations by sol-gel transcription. Circles indjcate Ag nanoparticles. 
silica species are adsorbed onto the cationic gelator fibrils and the polymerization further proceeds along these positively charged fibrils. This propagation mode can eventually yield the fibrous silica with a tubular or spherical structure (Figure 3).

Interestingly. since the sol-gel polymerization of TEOS was carried out in the presence of a noble metal ion such as $\mathrm{Ag}^{+}$ion, metal could be deposited on the surface of the resulting silica after calcination. With this intriguing idea in mind. we carefully took TEM images of silica obtained from hydrogel 1 with $\mathrm{Ag}^{-}$ion. Figure 3b reveals many small particles with $50 \mathrm{~nm}$ diameter inside the silica spheres. This result supports the view that $\mathrm{Ag}^{-}$ion complexed by hydrogelator 1 is dispersed in the superstructures and, after sol-gel polymerization followed by calcination, is retained within the silica structure. We believe that this metal deposition method is useful for the design of novel solid catalytic systems.

Representative nitrogen adsorption-desorption isotherms are shown in Figure 4. The tubular structure of the silica obtained from hydrogel 1 with $\mathrm{AgNO}_{3}$ has a BrunaterEmmett-Teller (BET) surface area of $661 \mathrm{~m}^{2} / \mathrm{g}$. On the other hand, the spherical structure of the silica obtained hydrogel 1 with $\mathrm{AgClO}_{4}$ showed BET surface area of $111 \mathrm{~m}^{2} / \mathrm{g}$.

In summary. the present study has demonstrated that the superstructures of hydrogel were controlled by the addition of metal ions. The novel tubular and spherical structures of the silica were obtained by sol-gel polymerization in the presence of metal ion. The morphologies of the silica nanomaterials were controlled by crown-appended sugar hydrogel with anions. Furthermore. the novel metal nanoparticles were deposited inside of the silica nanomaterials. We believe that various novel silica structures can be controlled using different anions in hydrogel complexes as a template

\section{Experimental Procedure}

Sol-gel polymerization of TEOS. Compound 1 (2 mg) and metal nitrate or perchlorate (10.0 equivalent) were dissolved in water $(160 \mathrm{mg})$ by heating. The gel sample was cooled to room temperature. TEOS (40 $\mathrm{mg}$ ) and benzylamine $(20 \mathrm{mg}$ ) as a catalyst were added to the gel sample. The sample was heated until a clear solution was obtained and then left at ambient temperature for 2-7 days. Subsequently, the sample was heated at $200^{\circ} \mathrm{C}$ for $2 \mathrm{~h}$, then 500 ${ }^{\circ} \mathrm{C}$ for $2 \mathrm{~h}$ under a nitrogen atmosphere, and finally, kept at $500^{\circ} \mathrm{C}$ under aerobic conditions for $4 \mathrm{~h}$.

Synthesis of compound 1 . Compound 1 was prepared by adaptation of synthetic methods published earlier. ${ }^{17}$ Light yellow solid. Mp: 190-191 ${ }^{\circ} \mathrm{C}$. ${ }^{1} \mathrm{H}$ NMR (300 MHz, DMSO$\left.\mathrm{d}_{6}\right): \delta 9.79(\mathrm{~s}, \mathrm{lH} .-\mathrm{NH}), 9.75$ (s, 1H, -NH), 7.48 (d, $2 \mathrm{H} . J=$ 9. $\mathrm{ArH}$ ). 7.31 (s. $1 \mathrm{H}, \mathrm{ArH}) .7 .07$ (d, lH. $J=8.4$. ArH). 6.95 (d. $1 \mathrm{H} . J=9 . \mathrm{ArH}) .6 .86(\mathrm{~d} .2 \mathrm{H} . J=9 . \mathrm{ArH}) .5 .30$ (d. $1 \mathrm{H} . J=$ 5.1. $-\mathrm{OH}$ ) 5.04 (d. $1 \mathrm{H}, J=5.1,-\mathrm{OH}) .4 .76$ (d. $1 \mathrm{H} . J=7.2$. $-\mathrm{OH}) .4 .58$ (t. $1 \mathrm{H} . J=7.2,-\mathrm{OH}$ ) 4.12 (q. $1 \mathrm{H} . J=5.4 .-\mathrm{CH}-$ ). 4.01 (m. 6H. -CH- \& - $\left.\mathrm{CH}_{2}-\right) .3 .75$ (m, 7H. - $\left.\mathrm{CH}-\&-\mathrm{CH}_{2}-\right)$. 3.34 (n. $\left.12 \mathrm{H} .-\mathrm{CH}_{2}-\right) .2 .25\left(\mathrm{~m}, 4 \mathrm{H},-\mathrm{CH}_{2}-\right) .1 .56(\mathrm{~m} .4 \mathrm{H}$.

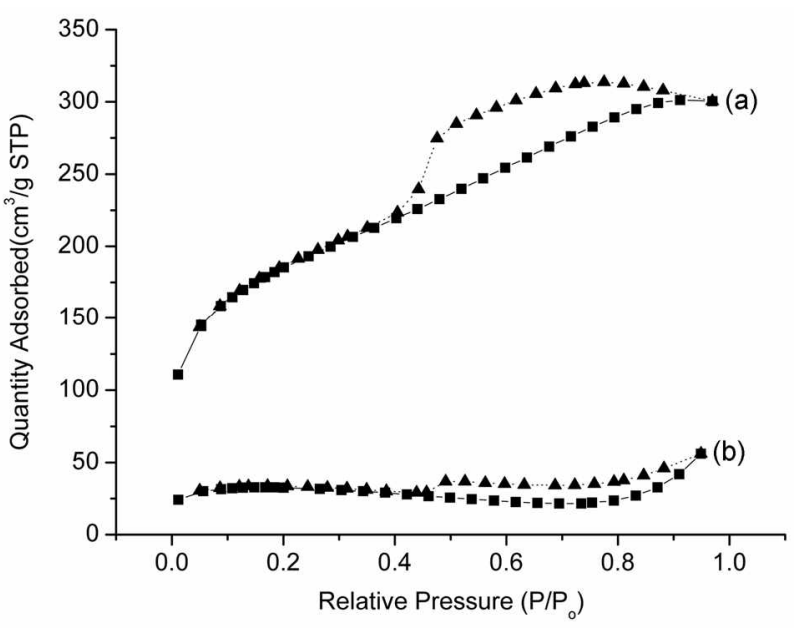

Figure 4. Nitrogen adsorption-desorption isotherms of (a) the silica nanotube obtained from $1+\mathrm{AgNO}_{3}$ and (b) the silica sphere obtained from $1+\mathrm{AgClO}_{4}$ by sol-gel transcription (-- $\mathbf{\Delta - -}$ desorption, -- $\mathbf{- - -}$ adsorption).

$-\mathrm{CH}_{2}-\mathrm{)} .1 .27$ (s. 12H, $-\mathrm{CH}_{2}-$ ): MS (FAB): $793(\mathrm{M}+\mathrm{H})^{-}$ (calcd MW $=792.91$ ); elemental analysis: calcd $(\%)$ for $\mathrm{C}_{41} \mathrm{H}_{611} \mathrm{~N}_{2} \mathrm{O}_{14}: \mathrm{C} 60.59, \mathrm{H} 7.63$. N 3.53, O 28.25: found: $\mathrm{C}$ 60.16. H 6.99. N 3.38

Acknowledgments. This work was supported by KOSEF (2008-01014 and 2008-01422). In addition, this work is supported by Korea Ministry of Environment as "The Ecotechnopia 21 Project".

\section{References}

1. Terech. P.: Weiss. R. G. Chem. Rev: 1997. 97.3133-3160.

2. Suzuki. M.: Nakajima. Y.: Yumoto. M.: Kimura. M.: Shirai. H.: Hanabusa, K. Langmior 2003, 19.8622-8624.

3. Moriyama M.: Mizoshita. N:; Yohota, T: Kıshımoto. K: Kato, T Ad, Hater: 2003. 15, 1335-1338.

4. Suzuki. M.: Nakajima. Y.: Yumoto. M.: Kimura. M.: Shirai. H.: Han1abusa. K. Okg. Bionol Chent 2004. 2. 1155-1159.

5. Lee. S. T.: Lee. S. S.: Kim. J. S.: Lee. T. Y.: Jung. T. H. Chent 1/ater: $\mathbf{2 0 0 5}, 17,6517-6520$.

6. Suzuki, M.: Owa, S.; Kimura, M.: Kurose. A.: Shırai. H. Hanabusa, K. Tetrahedron Lett. 2005, 46. 303-306.

7. Shirakawa. M.: Huiita. N.: Tanii. T.: Kaneko. K.: Shinkai. S. Chent. Conmum. 2005. $4149-4151$

8. George. M.: Weiss. R. G. Acc. Chem. Res 2006. 39. 489-497.

9. Suzuki, M.: Saıto, H.: Shıra, H.: Hanabusa. K. New d. Chem. 2007. $31,1654-1660$.

10. Ji. Q.: Kamiva. S.: Shimizu, T. Chem Lett. 2006. 35, 394-395.

11. Ji. Q.: Iwaura. R.: Shimizu. T. Chent. Mater 2007. 19. 1329-1334.

12. Kishida. T.: Huijta. N.: Sada. K.: Shinkai. S. J. Ant. Chent. Soc. 2005. 127. $7298-7299$.

13. Tanaka, S.: Shirakawa M.; Kaneko, K.: Takeuchi, M.: Shunkaı, S Langmuir 2005. 21. 2163-2172.

14. Jung. J. H.: Shinkai, S. Top. Cw Chem 2004. 248, 223-260.

15. Cho. E. J.: Teong. I. Y.: Lee. S. J.: Seo. J.: Kim. H. J.: Kim. E.: Lee. S. S.: Kang. J. K.: Kim1. J. S.: Tung. J. H. Bull. Konean Chen. Soc. $2007.28 .2519-2522$.

16. Jung. O.-S.: Kim. Y. J.: Lee, Y.A.: Park. K.-M.: Lee. S. S. Inorg Chen. 2003, $+2,844-850$

17. Jung. J. H.; Rim, J. A.: Cho. E. J.; Lee. S. J.; Jeong, I. Y:; Kameda, N. Tetrahedron $2007.63 .7449-7456$ 